J. G. Pinto, Vítor Monteiro, Bruno Exposto, Luis Barros, Tiago Sousa, Luis Monteiro, João L. Afonso,

"Power Electronics Converters for an Electric Vehicle Fast Charging Station with Storage Capability" in

Green Energy and Networking, 1st ed., J. L. Afonso, V. Monteiro, and J. G. Pinto, Eds. Springer

International Publishing, 2019, pp. 119 -130. ISBN: 978-3-030-12949-1 (Print), ISBN:978-3-030-12950-7

(Online) DOI: 10.1007/978-3-030-12950-7_10

\title{
Power Electronics Converters for an Electric Vehicle Fast Charging Station with Storage Capability
}

\author{
J. G. Pinto ${ }^{1}$, Vitor Monteiro ${ }^{1}$, Bruno Exposto ${ }^{1}$, Luis A. M. Barros ${ }^{1}$, Tiago J. C. Sousa ${ }^{1}$, \\ L. F. C. Monteiro ${ }^{2}$ and João L. Afonso ${ }^{1}$ \\ ${ }^{1}$ Centro ALGORITMI, University of Minho, Campus de Azurém, Guimarães, Portugal. \\ gabriel.pinto@algoritmi.uminho.pt \\ ${ }^{2}$ State University of Rio de Janeiro, Electronics Engineering Program, Campus F. Negrão de \\ Lima 20559-900, Rio de Janeiro, Brazil.
}

\begin{abstract}
Fast charging stations are a key element for the wide spreading of Electric Vehicles (EVs) by reducing the charging time to a range between 20 to 40 minutes. However, the integration of fast charging stations causes some adverse impacts on the Power Grid (PG), namely by the huge increase in the peak demand during short periods of time. This paper addresses the design of the power electronics converters for an EV DC fast charging station with local storage capability and easy interface of renewables. In the proposed topology, the energy storage capability is used to smooth the peak power demand, inherent to fast charging systems, and contributes to the stability of the PG. When integrated in a Smart Grid, the proposed topology may even return some of the stored energy back to the power grid, when necessary. The accomplishment of the aforementioned objectives requires a set of different power electronics converters that are described and discussed in this paper.
\end{abstract}

Keywords: Power Electronics; Electric Vehicles; DC Fast Charging; Energy Storage System.

\section{Introduction}

In recent years, a major concern with climatic changes and energy efficiency have made the electrification of the transport sector a major field of research. Although there are vehicles that are fed directly from the Power Grid (PG), as is the case of railway electric locomotives, a great number of Electric Vehicles (EVs) will be powered from batteries, motivating the research of battery charging systems for EVs [1], [2].

Worldwide, there are three organizations working in the standardization of electrical vehicle charging equipment, namely the Society of Automotive Engineering (SAE), the CHAdeMO association and the International Electrotechnical Commission (IEC). The IEC 61851 defines four different charging modes: Mode 1 refers to the slow charge in $\mathrm{AC}$ with a maximum current of 16 A per phase $(3.7 \mathrm{~kW}-11 \mathrm{~kW})$ and the EV connection to the AC PG uses standard power connections; Mode 2 refers to the slow charge in $\mathrm{AC}$ with a maximum current of $32 \mathrm{~A}$ per phase $(3.7 \mathrm{~kW}-22 \mathrm{~kW})$ and the EV con- 
nection to the AC PG requires a specific power connection with an intermediate electronic device with a pilot control function and protections; Mode 3 refers to the slow or semi-quick charge in AC with a maximum current of $63 \mathrm{~A}$ per phase $(<43 \mathrm{~kW})$ and the $\mathrm{EV}$ connection to the AC PG requires a specific device; Mode 4 refers to a DC charging, with a maximum DC current of $400 \mathrm{~A}(<240 \mathrm{~kW})$, where an external charger is required [3]. However, the PGs were not prepared to withstand this new type of loads or the peaks of demand that they can cause, therefore the impact caused by the proliferation of EVs cannot be neglected [4], [5]. The integration of EVs in the PGs will be an interesting challenge to the future Smart Grids [6], [7].

In order to reduce the negative effects and to facilitate the integration of EVs, some authors propose the use of bidirectional on-board chargers, enabling the Vehicle-to-Grid (V2G) mode of operation, which allows returning part of the stored energy back to the PG [7], [8], and the Vehicle-to-Home (V2H), where the charging power of the $\mathrm{EV}$ is continuously adjusted as a function of the home electric appliances [9]. With respect to DC fast chargers (off-board chargers) the main concern is related with the impacts to the power grid in terms of harmonics and peak demand [10]. The time required for a fast EV battery charging depends on the battery capacity and on its Stateof-Charge (SoC). However, usually it does not exceed 20 to 40 minutes considering a charging power of $50 \mathrm{~kW}$ [11]. Despite the relatively short charging times, in a station with several charging posts, there will be situations where several EVs are charging simultaneously and in other occasions no EV is charging, resulting in a highly intermittent power consumption from the power grid. In this way, the simultaneous fast charging of a large number of EVs represents a significant oscillation in the power demand that can be problematic, especially in weak power systems, like islands or remote villages [12]. To mitigate these negative impacts, several studies have been conducted. A concept of low voltages DC-Buses, including power buffers based in Battery Energy Storage Systems (BESS) is proposed in [13]. In [14], it is addressed the design of a DC fast charging station coupled with a local battery energy storage. In [15] is proposed an optimal EV fast charging infrastructure, where the EVs are connected to a DC-Bus, employing an individual control for the charging process in order to optimize the power transfer from the AC PG to the DC-Bus. Other studies propose the integration of renewables connected to DC fast charging stations [16], [17].

Due to the increasing number of EV charging and discharging cycles over time, the capacity of the EVs batteries reduces, and consequently the EV range decreases, thereby it is necessary to proceed with the replacement. However, these batteries can be used in applications where the charge density is not significant. Considering that the batteries of the EVs have a charge density of about $70 \%$ of the initial value after 10 years of use [18], the replaced batteries can be reused in stationary Energy Storage Systems (ESS) to smooth the peak demand of the EV fast charging stations. In [19] is presented a study demonstrating that the integration of BESS and renewables in DC charging stations can be also economically advantageous. 


\section{Power Converters for the Proposed Charging Station}

The proposed topology for the EV fast charging station is presented in Fig. 1, which consists of a set of power converters sharing the same DC-Bus, including a high capacity ESS. The first converter interfaces the DC-Bus with the PG. To prevent power quality problems in the PG, this converter may operate with sinusoidal currents and unitary power factor from the PG side. Several converter topologies can be used to accomplish this task. In order to increase flexibility and taking into account the convergence for Smart Grids, it can be useful to allow a two-way energy flow. Therefore, taking into account the application and the required nominal power, a three-phase two-level interleaved converter can be a good solution.

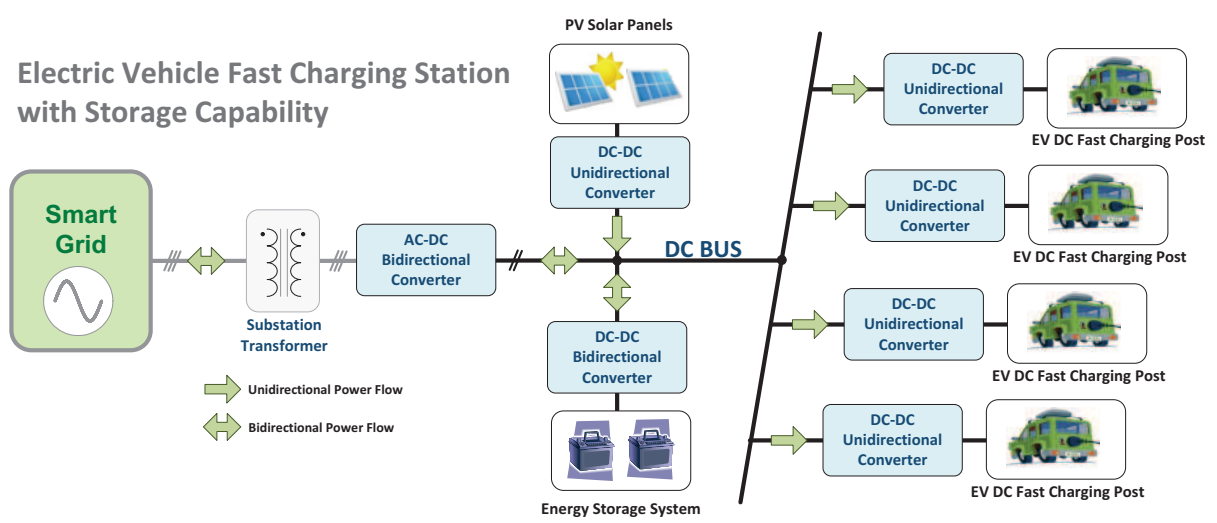

Fig. 1. Block diagram of the proposed topology for the EV fast charging station with storage capability.

Fig. 2 presents the power circuit of the bidirectional AC-DC converter used to interface the PG with the DC-Bus. It consists of a three similar three-phase IGBT bridges sharing the same DC-Bus with a second order low-pass LC passive filter in the PG side.

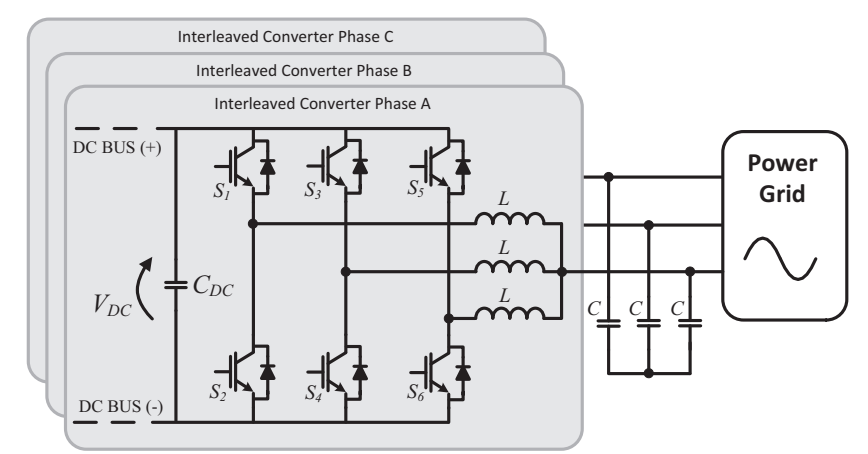

Fig. 2. Three-phase interleaved bidirectional AC-DC power converter used to interface the power grid with the DC-Bus of the EV fast charging station. 
To charge the EVs batteries independently, it is necessary a DC-DC converter for each charging post. To accomplish with the usual battery charging recommendations, a possible solution for this task is a buck-type converter with constant current output.

Taking into account the application and the nominal power of the converter $(50 \mathrm{~kW})$, instead of a buck-type converter, it can be used an interleaved topology which allows to decrease the switching frequency and the power rating of each semiconductor, while maintaining a low battery current ripple. Fig. 3 presents the power circuit of the interleaved buck-type constant output current converter.

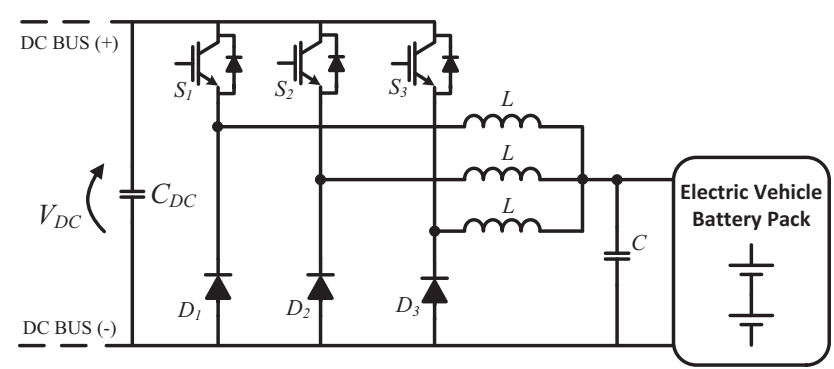

Fig. 3. Interleaved buck-type DC-DC power converter used to interface the DC-Bus of the fast charging station with the EV battery pack.

The batteries used to the load shift purposes must interface the DC-Bus with a bidirectional DC-DC converter. To prevent problems that may occur with parallel connection of individual battery cells it is recommendable that each pack of individual battery cells connected in series has its own DC-DC converter. The adoption of individual DCDC converters for each battery pack also endows the system with fault tolerance capability. To preserve the batteries state of health, the DC-DC power converter should operate with constant current from the batteries side. A good solution to accomplish this task can be a buck-boost bidirectional converter. Taking into account the power rating of the converter, it can be used the interleaved bidirectional buck-boost DC-DC converter that is presented in Fig. 4. This converter operates as a buck-type converter to transfer energy from the DC-Bus to the BESS and operates as a boost-type converter to transfer energy in the opposite way.

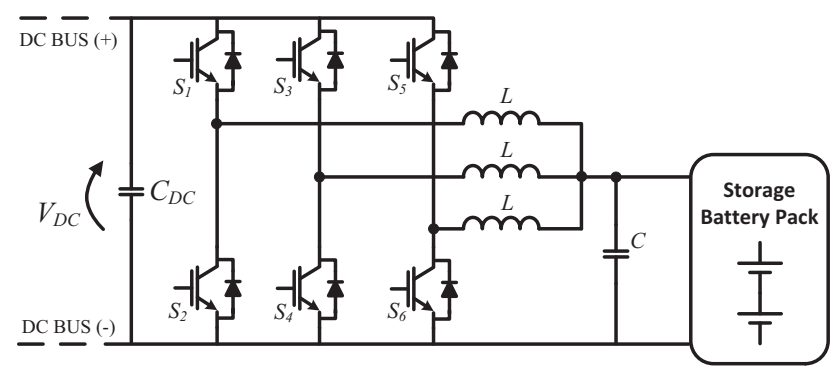

Fig. 4. Interleaved bidirectional buck-boost DC-DC converter used to interface the DC-Bus of the fast charging station with the BESS. 
With the proposed topology for the DC fast charging station, the interface with renewable energy became simplified because it is possible to use a simple DC-DC converter. For example, to interface an array of photovoltaic solar panels, it can be used a boost-type converter with constant input current. In function of the maximum power from the photovoltaic solar panels, it can be adopted a simple boost-type or an interleaved converter with 2 or 3 legs, as represented in Fig. 5. However, the power available in the photovoltaic installation is not constant over timer, being necessary to implement a Maximum Power Point Tracker (MPPT) control algorithm in order to find the Maximum Power Point (MPP) and force the power converter to operate at that point.

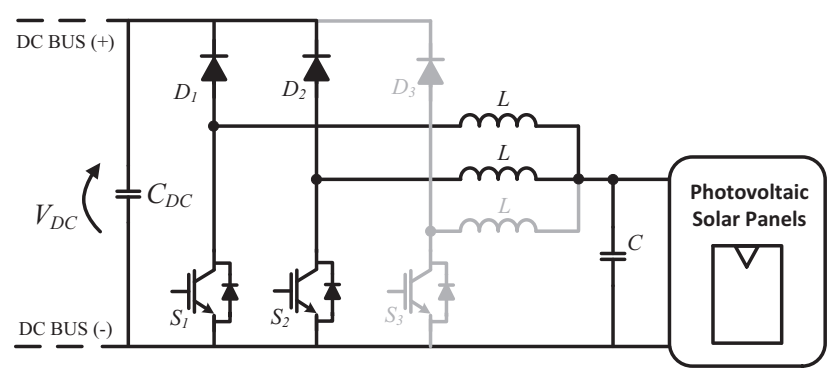

Fig. 5. Interleaved boost-type DC-DC converter used to interface an array of photovoltaic solar panels with the DC-Bus of the DC fast charging station.

\section{Power Converters Control}

The three-phase bidirectional AC-DC power converter used to interface the PG with the DC-Bus of the EV fast charging station is presented in Fig. 2. It should be controlled to absorb the required active power $\left(P^{*}\right)$, imposing sinusoidal currents and a unitary power factor, avoiding distortions in the PG voltages. To accomplish with this task, it is used a digital Phase-Locked Loop (PLL) algorithm implemented in the $\alpha-\beta$ coordinates to synchronize the controller with the positive sequence of the PG fundamental voltages [20]. From the PLL algorithm it results three sinusoidal signals with unitary amplitude, representing the positive sequence of the PG voltages. These signals are then multiplied by the reference current rms value to obtain the AC reference currents. The reference currents are then applied to a predictive current control that produces the reference voltages that the converter must produce [21]. The reference voltages are then compared with a triangular carrier to produce the gate signals to be applied to the IGBTs. To enhance the quality of the obtained currents, it is used a strategy to compensate the nonlinearities introduced by the dead-time [22]. The block diagram of the threephase bidirectional AC-DC converter control system is presented in Fig. 6.

According to the majority of battery supplier's recommendations, the EV fast charging must be done with a constant current [23]. Therefore, the interleaved buck-type DC-DC power converter used to interface the DC-Bus with the EV battery pack is controlled to produce a constant output current $\left(I_{B A T}\right)$. Usually, the maximum charging current is determined by the EV Battery Management System (BMS) and its value is transmitted to the fast charger controller [23]. 


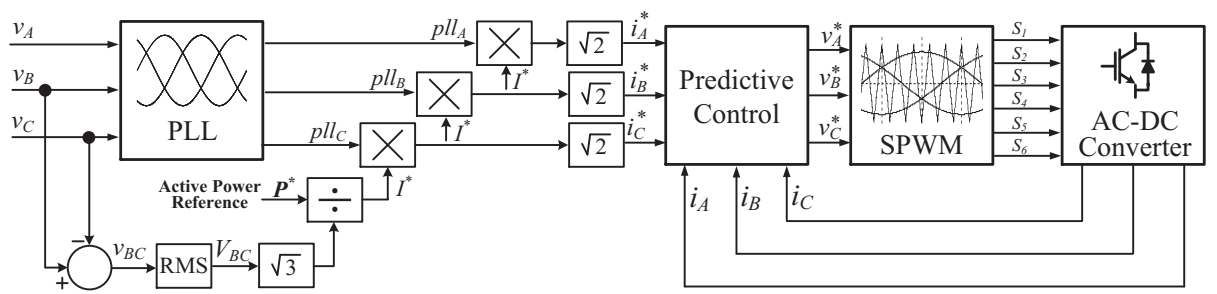

Fig. 6. Block diagram of the three-phase bidirectional AC-DC converter control system.

To accomplish with the fast charging it is used a Proportional Integral (PI) controller to ensure that the output current correctly follows the set points defined by the BMS. The output of the proportional integral controller is compared with three triangular carriers with the same amplitude and a phase-shift of $120^{\circ}$ between them to generate the IGBTs pulse pattern for an interleaved operation. As mentioned above, the use of an interleaved converter allows to reduce the size of the passive output filter and to maintain a low value for the IGBTs switching frequency. The block diagram of the buck-type DC-DC converter control system is presented in Fig. 7.

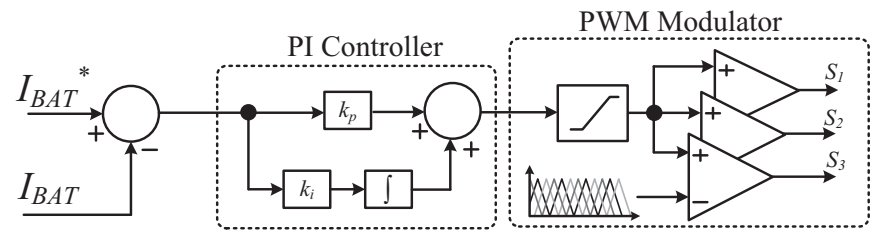

Fig. 7. Block diagram of the buck-type DC-DC converter control system.

The interleaved bidirectional DC-DC converter, used to interface the DC-Bus of the fast charging station with the storage battery pack, is controlled using a PI controller to maintain the voltage of the DC-Bus $\left(V_{D C}\right)$ regulated. Since the converter is bidirectional, if the power absorbed from the PG is higher than the power used in the charging posts, the DC-Bus voltage tends to increase and the converter sends energy to the storage battery packs to maintain the DC-Bus voltage regulated. During this mode, the bottom IGBTs of each converter leg are kept open, while the top IGBTs are switched at a fixed frequency. If the power absorbed from the PG is lower than the power used in the charging posts, the converter gets energy from the BESS to maintain the DC-Bus voltage regulated. During this mode, the top IGBTs are kept open and the bottom IGBTs are switched. To control the IGBTs of the proposed converter, three triangular carriers are used with the same amplitude and a phase-shift of $120^{\circ}$ between them. Due to the $120^{\circ}$ phase-shift between the triangular carriers, the ripple frequency in the batteries current is three times higher than the ripple frequency in each output inductor. This allows to reduce the size of the passive filters, while keeping a low value of switching frequency. The total charging current is also divided by the three legs, allowing a reduction in the IGBTs power rating. The block diagram of the bidirectional DC-DC converter control system is presented in Fig. 8. 


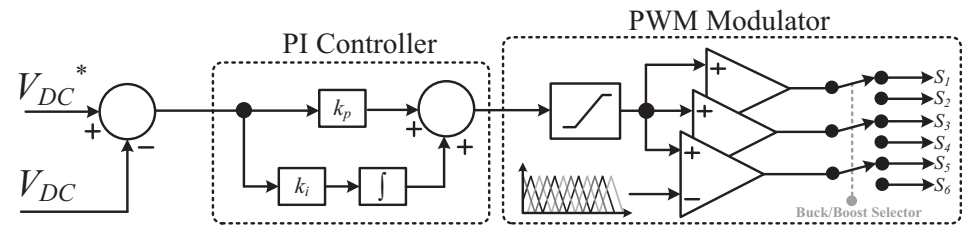

Fig. 8. Block diagram of the bidirectional DC-DC converter control system.

Currently, the vehicles filling stations always have some kind of protection for users against climatic phenomena, where it is usually used a roof to cover the entire area of the gas station. In many cases, this roof is an excellent location to install photovoltaic solar panels. In this case, it can be interesting to interface the solar panels directly to the DC-Bus of the fast charging station, avoiding the utilization of a DC-AC converter. Depending on the photovoltaic solar panels peak power, it can be advantageous to choose an interleaved converter instead of the simple boost-type converter. The controller of the interleaved boost-type DC-DC converter used to interface an array of photovoltaic solar panels with the DC-Bus should maximize the power extracted from the photovoltaic solar panels. Therefore, it is important to use a MPPT algorithm to control this converter. The main general characteristics that distinguish the MPPT algorithms are: panel independence, convergence speed, tracking efficiency, implementation complexity and robustness [24]. The panel independency is an important characteristic, because avoids the determination of some parameters of the PV array empirically, to different irradiance and temperature levels. Besides, if the parameters vary, the previous measurements can become outdated and, therefore, the MPPT will lose the convergence for the MPP. The convergence speed is important, because under sudden changes, if the MPPT is not able to a fast convergence, a considerable amount of energy can be lost in that transient. A good tracking performance ensures that the harvested energy is maximized. This is particularly important in situations when the solar radiation is minimal. Considering these premises, the incremental conductance algorithm can be a good choice. The incremental conductance algorithm works based on the fact that the slope of the photovoltaic solar panel power curve is zero at the MPP, positive on the left of the MPP, and negative on the right. Therefore, this method can determine that the MPP has been reached and interrupt the perturbing of the operating point. The advantages of the incremental conductance algorithm are the calculation of the direction to perturb the operating point to reach the MPP and the actual determination of the MPP reaching. Also, incremental conductance can track sudden increases or decreases of solar irradiance conditions with higher accuracy than algorithms based on perturb and observe [24]. The output of the MPPT algorithm is then compared with the triangular carriers to obtain the IGBTs pulse patterns. In the case of a single boost-type converter adoption, it must be used a single triangular carrier. In the case of a two-leg interleaved converter, two triangular carriers with a phase shift of $180^{\circ}$ must be used. A three-leg interleaved converter requires three triangular carriers with a phase shift of $120^{\circ}$ between them. The block diagram of the boost DC-DC converter control system is presented in Fig. 9. 


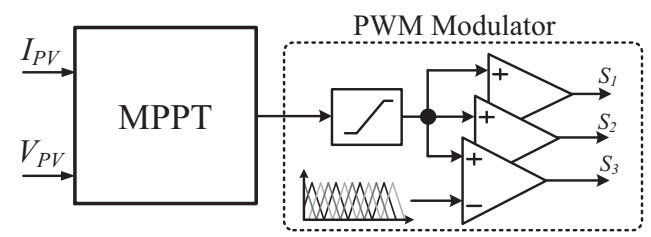

Fig. 9. Block diagram of the boost DC-DC converter control system.

\section{Simulations of the Proposed System}

In order to validate the hardware topologies and the control algorithms of the converters used in the fast DC fast charging stations, it was developed a simulation model using PSIM. PSIM is a simulation software from Powersim Inc. specially designed for power electronics.

The most common EVs are equipped with battery packs whose nominal voltage ranges between $300 \mathrm{~V}$ and $420 \mathrm{~V}$. Therefore, the DC-Bus voltage was defined to $450 \mathrm{~V}$. Thus, the individual converter of each charging post always operates in buck mode. In order to optimize the power converters in terms of efficiency, it was selected an AC phase to phase voltage around $300 \mathrm{~V}$. As the service station connects to the PG in medium voltage, it is possible to choose a transformer with the required secondary voltage. In the simulation, it is used a transformer with a secondary voltage of $300 \mathrm{~V}$. However, the system can be easily dimensioned to operate with different voltage levels, if required.

In Fig. 10 and Fig. 11 are presented some simulation results of the three-phase interleaved bidirectional AC-DC power converter used to interface the PG with the DC- Bus. Fig. 10 presents the instantaneous power, the voltages and the currents in the $\mathrm{AC}$ side of this converter. As it is possible to see, although the voltages are distorted, the currents produced by the converter are sinusoidal as required. In consequence of the PG voltage distortions, the instantaneous power oscillates around $170 \mathrm{kVA}$, which corresponds to the absorbed active power.

Fig. 11 shows in detail the interleaved effect in the produced currents. Fig. 11 (a) shows the current in each of the output inductors in the phase $A$, and Fig. 11 (b) shows the total current of the phase $A$, which corresponds to the sum of the currents in the three inductors. As it is possible to see, the total output current presents a ripple frequency three times higher than the ripple frequency in each of the inductors, with a frequency three times greater. In the simulation, the IGBTs switching frequency was fixed in $10 \mathrm{kHz}$, and each of the three inductors presents a value of $750 \mu \mathrm{H}$. In combination with the inductor are also used three $20 \mu \mathrm{F}$ capacitors, allowing a further reduction of the current ripple. 

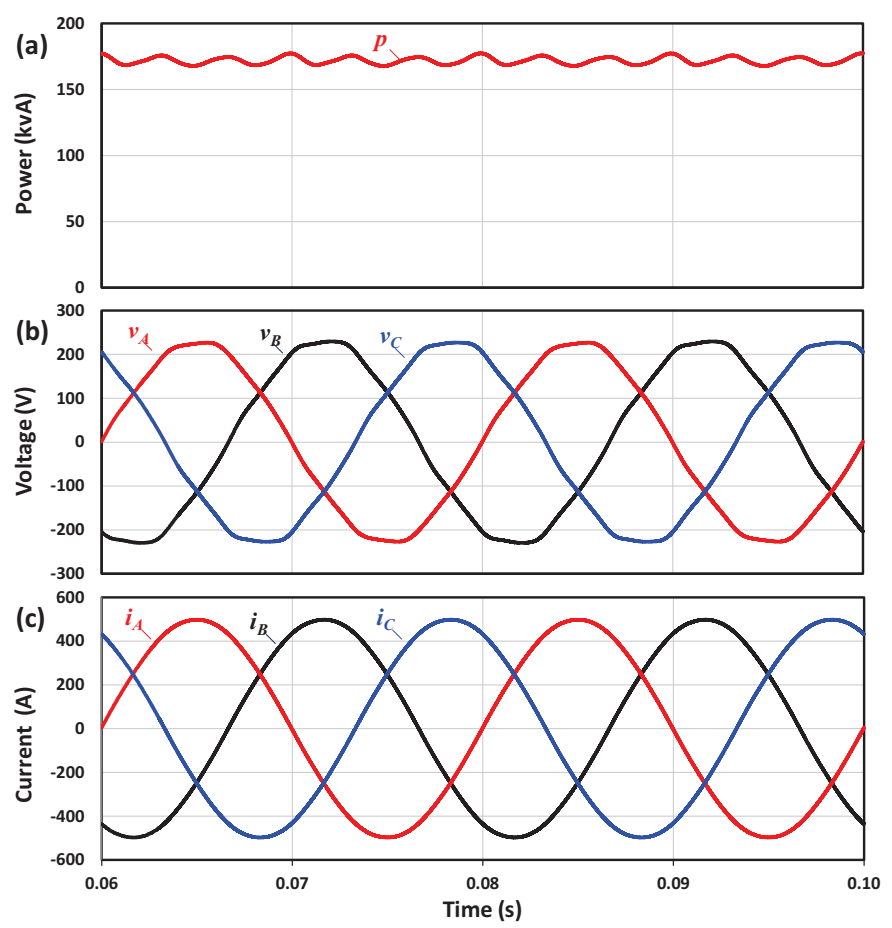

Fig. 10. Simulation results of the three-phase interleaved bidirectional AC-DC power converter used to interface the PG with the DC-Bus: (a) Instantaneous input power, $p$; (b) PG voltages, $v_{A}, v_{B}$ and $v_{C}$; (c) PG currents, $i_{A}, i_{B}$ and $i_{C}$.
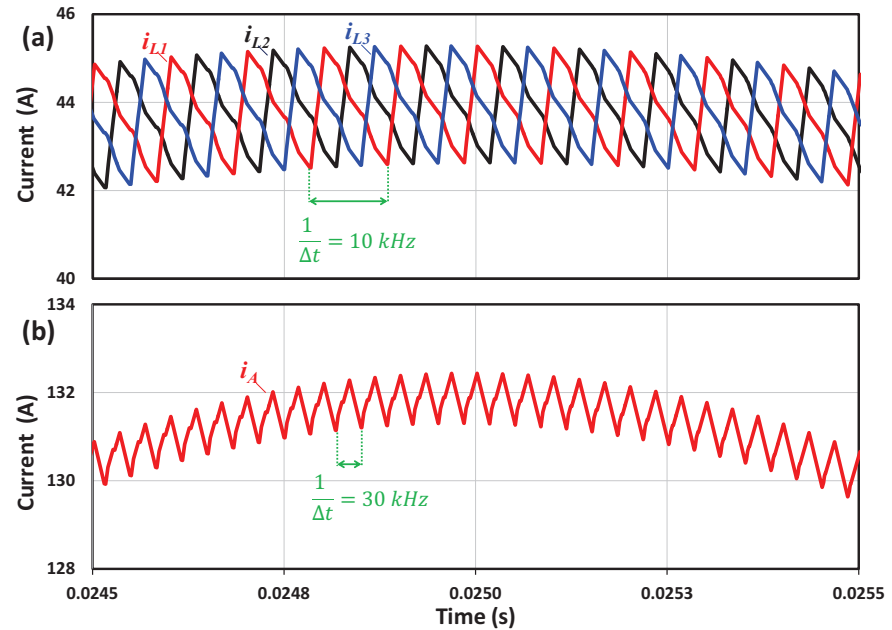

Fig. 11. Simulation results of the three-phase interleaved bidirectional AC-DC power converter used to interface the power grid with the DC-Bus: (a) Current in the phase $A$ output inductors, $i_{L 1}, i_{L 2}$ and $i_{L 3}$; (b) Total Current of the phase $A, i_{A}$. 
In Fig. 12 is presented a simulation result of the interleaved buck-type DC-DC power converter used to interface the DC-Bus of the fast charging station with an EV battery pack. Fig. 12 (a) shows the current in each of the output inductors of the converter, and Fig. 12 (b) shows the total current, which corresponds to the sum of the currents in the three inductors. In the simulation, the switching frequency of the IGBTs was fixed in $15 \mathrm{kHz}$, and each of the three inductors presents a value of $500 \mu \mathrm{H}$. In combination with the inductors are also used three capacitors with a value of $100 \mu \mathrm{F}$ to reduce the ripple in the battery current.

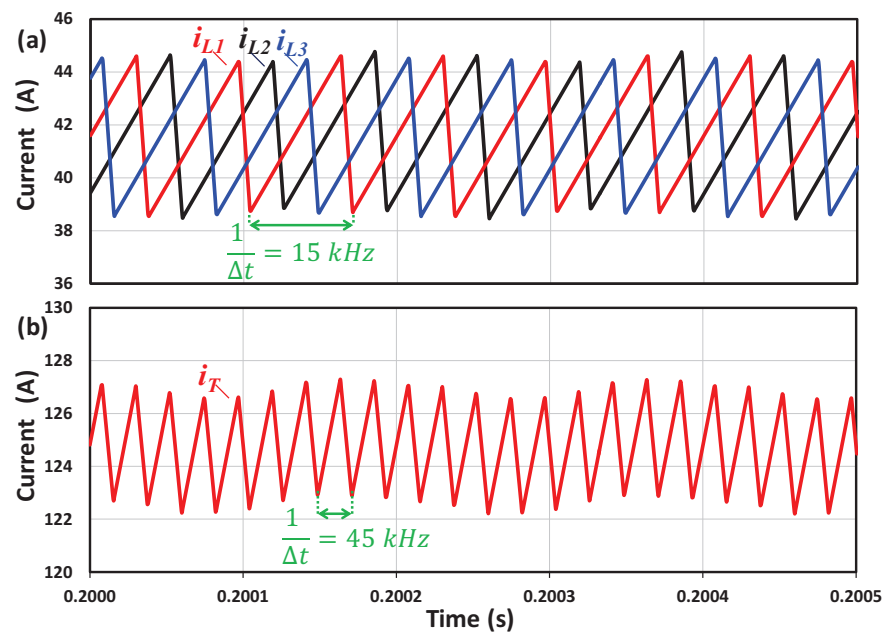

Fig. 12. Simulation results of the interleaved buck-type DC-DC power converter used to interface the DC-Bus of the DC fast charging station with the EV battery pack: (a) Current in the output inductors, $i_{L 1}, i_{L 2}$ and $i_{L 3} ;$ (b) Total current, $i_{T}$.

\section{Conclusion}

In this paper, a new concept of a DC fast charging station for EVs is presented. The main advantages of the proposed topology are the storage capability and the easy integration of renewable energy sources. The ESS in this proposed charging station can be mainly composed by electrochemical batteries, reused from EVs. The system is composed by a set of power converters. One AC-DC bidirectional converter is used to interface the DC-Bus of the charging station with the PG. The interface with the storage batteries is done by means of bidirectional DC-DC converters, one converter for each battery pack. The charging posts are implemented by means of buck-type DC-DC converters, one for each individual charging point. The interface of renewables can be implemented by means of a simple DC-DC converter. In terms of performance, the proposed topology with the suggested storage system allows a significant reduction in the maximum power absorbed from the PG. The topology of the proposed solution was 
defined taking into account the required power for each one of the converters. The proposed topologies and control algorithms were validated through computer simulations developed with the software PSIM.

\section{Acknowledgement}

This work has been supported by COMPETE: POCI-01-0145-FEDER-007043 and by FCT within the Project Scope: UID/CEC/00319/2013. This work is financed by the ERDF-COMPETE 2020 Programme, and FCT within project SAICTPAC/0004/2015-POCI-01-0145-FEDER-016434 and FCT within project PTDC/EEI-EEE/28813/2017. Mr. Luis A. M. Barros is supported by the doctoral scholarship PD/BD/143006/2018 granted by the Portuguese FCT agency. Mr. Tiago Sousa is supported by the doctoral scholarship SFRH/BD/134353/2017 granted by the Portuguese FCT agency.

\section{References}

1.Kaushik Rajashekara, "Present Status and Future Trends in Electric Vehicle Propulsion Technologies," IEEE J. Emerg. Sel. Topics Power Electron., vol.1, no.1, pp.3-10, Mar. 2013.

2.Ali Emadi, Young Joo Lee, Kaushik Rajashekara, "Power Electronics and Motor Drives in Electric, Hybrid Electric, and Plug-In Hybrid Electric Vehicles,” IEEE Trans. Ind. Electron., vol.55, pp.2237-2245, June 2008.

3.Gjelaj, Marjan; Træholt, Chresten; Hashemi Toghroljerdi, Seyedmostafa; Andersen, Peter Bach, "Optimal Design of DC Fast-Charging Stations for EVs in Low Voltage Grids" Proceedings of 2017 IEEE Transportation Electrification Conference, 2017, DOI: 10.1109/ITEC.2017.7993352.

4.Seshadri Srinivasa Raghavan, Alireza Khaligh, "Electrification Potential Factor: EnergyBased Value Proposition Analysis of Plug-In Hybrid Electric Vehicles," IEEE Trans. Veh. Technol., vol.61, no.3, pp.1052-1059, Mar. 2012.

5.Shengnan Shao, Manisa Pipattanasomporn, Saifur Rahman, "Grid Integration of Electric Vehicles and Demand Response with Customer Choice," IEEE Trans. Smart Grid, vol.3, no.1, pp.543-550, Mar. 2012.

6.João A. Peças Lopes, Filipe Soares, Pedro M. Rocha Almeida, "Integration of Electric Vehicles in the Electric Power Systems," Proc. IEEE, vol.99, no.1, pp.168-183, Jan. 2011.

7.Vehbi C. Güngör, Dilan Sahin, Taskin Kocak, Salih Ergüt, Concettina Buccella, Carlo Cecati, Gerhard P. Hancke, "Smart Grid Technologies: Communication Technologies and Standards," IEEE Trans. Ind. Informat., vol.7, no.4, pp.529-539, Nov. 2011.

8.Vítor Monteiro, J. G. Pinto, João L. Afonso, "Operation Modes for the Electric Vehicle in Smart Grids and Smart Homes: Present and Proposed Modes", IEEE Transactions on Vehicular Technology, vol. 65, no. 3, pp. 1007-1020, Mar. 2016. ISSN: 0018-9545, DOI: 10.1109/TVT.2015.2481005.

9.J. G. Pinto, Vítor Monteiro, Henrique Gonçalves, João L. Afonso, “Onboard Reconfigurable Battery Charger for Electric Vehicles With Traction-to-Auxiliary Mode”, IEEE Transactions on Vehicular Technology, vol.63, no.3, pp.1104-1116, Mar. 2014. ISSN 0018-9545, DOI: 10.1109/TVT.2013.2283531. 
10.Sanzhong Bai, Srdjan M. Lukic, "Unified Active Filter and Energy Storage System for an MW Electric Vehicle Charging Station," IEEE Trans. Power Electron., vol.28, no.12, pp.5793-5803, Dec. 2013.

11.Efacec "QC 50 Quick Charger," Efacec - Portfolio of Products, 2008.

12.Vítor Monteiro, M. J. Sepúlveda, J. C. Aparício Fernandes, J. G. Pinto, João L. Afonso. "Evaluation of the Introduction of Electric Vehicles in the Power Grid - A Study for the Island of Maio in Cape Verde", in CONTROLO 2016 Portuguese Conference on Automatic Control, 14-16 September, Guimarães, Portugal, pp.713-724, DOI: 10.1007/978-3-31943671-5_60 ISBN: 978-3-319-43670-8 (Print) 978-3-319-43671-5 (Online).

13.M. Vasiladiotis, A. Rufer and A. Béguin, "Modular converter architecture for medium voltage ultra fast EV charging stations: Global system considerations," 2012 IEEE International Electric Vehicle Conference, Greenville, SC, 2012, pp. 1-7. doi: 10.1109/IEVC.2012.6183228

14.M. Gjelaj, C. Træholt, S. Hashemi and P. B. Andersen, "DC Fast-charging stations for EVs controlled by a local battery storage in low voltage grids," 2017 IEEE Manchester PowerTech, Manchester, 2017, pp. 1-6. doi: 10.1109/PTC.2017.7980985

15.Samir Shariff, Mohammad Saad Alam, Furkan Ahmad, Wajahat Khan, "Optimal Electric Vehicle Fast Charging Infrastructure, proceedings of The Intelligent Transportation Society of America 2018 annual meeting, Detroit, Michigan, June 4-7, 2018

16.Vítor Monteiro, J. G. Pinto, João L. Afonso, "Experimental Validation of a Three-Port Integrated Topology to Interface Electric Vehicles and Renewables with the Electrical Grid", IEEE Transactions on Industrial Informatics, vol.14, no.6, pp 2364-2374, June 2018. DOI: 10.1109/TII.2018.2818174.

17.Cheddadi Youssef, Errahimi Fatima, Es-sbai najia and Alaoui Chakib, "A technological review on electric vehicle DC charging stations using photovoltaic sources, IOP Conference Series: Materials Science and Engineering, volume 353, 2018. doi:10.1088/1757899X/353/1/012014

18.ABB, "ABB and partners to evaluate the reuse of the Nissan LEAF battery for commercial purposes," Zurich, Switzerland, Jan. 2012.

19.J. G. Pinto, Vítor Monteiro, Delfim Pedrosa, João L. Afonso "Economic Assessment of a Public DC Charging Station for Electric Vehicles with Load Shift Capability" in Proceedings of the 3rd International Conference on Energy and Environment: bringing together Economics and Engineering - ICEE 2017, 29-30 June 2017, Porto, Portugal, pp. 460-466, ISBN:978972-95396-9-5, ISSN:2183-3982.

20.Luís Guilherme Barbosa Rolim, Diogo Rodrigues Costa, Maurício Aredes, "Analysis and Software Implementation of a Robust Synchronizing PLL Circuit Based on the pq Theory," IEEE Trans. Ind. Electron., vol.53, no.6, pp.1919-1926, Dec. 2006.

21.S. Orts-Grau, F. J. Gimeno-Sales, A. Abellan-Garcia, S. Segui-Chilet, J. C. Alfonso-Gil, "Improved Shunt Active Power Compensator for IEEE Standard 1459 Compliance," IEEE Trans. Power Del., vol.25, no.4, pp.2692-2701, Oct. 2010.

22.Alfredo R. Munoz, Thomas A. Lipo, "On-Line Dead-Time Compensation Technique for Open-Loop PWM-VSI Drives,” IEEE Trans. Power Electron., vol.14, no.4, pp.683-689, July 1999.

23.J. Qiang, L. Yang, G. Ao and H. Zhong, "Battery Management System for Electric Vehicle Application," 2006 IEEE International Conference on Vehicular Electronics and Safety, Shanghai, 2006, pp. 134-138. doi: 10.1109/ICVES.2006.371569

24.Trishan Esram, Patrick L. Chapman, "Comparison of Photovoltaic Array Maximum Power Point Tracking Techniques,” IEEE Trans. Energy Convers., vol.22, no.2, pp.439-449, June 2007. 